\title{
Nicolás Ruiz: \\ LA LUCHA CONTRA EL ESTADO Y LA RESTRICCIÓN INTERNA DE DERECHOS
}

\author{
Inés Castro Apreza
}

Resumen: Desde una perspectiva histórica, en este articulo se analiza el desarrollo político-electoral de Nicolás Ruiz, un municipio de los Valles Centrales de Chiapas; se pone el énfasis en el periodo que comienza en 1994, cuando sus habitantes cambian de opción politica. Se muestra que es un caso paradigmático de una población mayoritaria con reivindicaciones frente al gobierno local y el Estado nacional, al tiempo que la asamblea de comuneros impone restricciones internas que limitan o anulan los derechos comunales y los derechos politicos de sus habitantes.

Palabras clave: derechos, usos y costumbres, asamblea de comuneros, elecciones, comunidad, minorías politicas.

Enviado a dictamen: 15 de febrero de 2007.

Aprobación: 26 de marzo de 2007.

Inés Castro Apreza, doctora en sociología e investigadora del Centro de Estudios Superiores de México y Centroamérica de la Universidad de Ciencias y Artes de Chiapas. Pertenece al cuerpo académico de "Política, Diferencia y Fronteras". Se ha especializado en los temas de ciudadanía, democracia y género. Ha sido consejera electoral distrital (2005-2006) y, durante 2001, directora de investigación del Instituto Chiapaneco de la Mujer, correo electrónico: castroapreza@yahoo.com.mx.
Abstract: From an historical perspective, this article analyses the case of Nicolás Ruiz, a municipality of Chiapas. It focuses on its political-electoral evolution to be centered in the period that begins in 1994, when the inhabitants change their political options. It is shown that it is a paradigmatic case of a majority population with vindications in front of the local government and the national State, at the time that the comuneros assembly imposes internal restrictions that limit or they annul the communal rights and the political rights of its inhabitants.

Key words: rights, uses and customs, comuneros assembly, elections, community, political minorities.

$\mathrm{H}$ asta 1994, poco se sabía de Nicolás Ruiz, un municipio enclavado en los Valles Centrales del estado de Chiapas, colindante con los de Venustiano Carranza y Totolapa, al que todavía hoy los estudios siguen dedicando una escasa atención (Shannon, 2004; Lisbona, 1992), y ello aún cuando desde aquel año, marcado históricamente por la aparición pública del Ejército Zapatista de Liberación Nacional (EZLN), la gran capacidad de movilización política de los sandiegueros $^{1}$ pasó a convertirse en la nota dominante de la historia reciente del municipio.

Con anterioridad a 1994 y en marcado contraste con el historial político de sus vecinos,

\section{7}


los hombres y las mujeres de Nicolás fueron "pacíficos" y las cifras electorales revelan una completa unanimidad en la definición del voto en torno al Partido Revolucionario Institucional (PRI). Con la llegada del 94, Nicolás da un giro de ciento ochenta grados en su trayectoria política al retirar su apoyo al PRI y ofrecer el conjunto de sus votos al Partido de la Revolución Democrática (PRD), así como, particularmente entre 1994 y 2000 , sumar a una buena parte de su población a las bases de apoyo del EZLN, con lo que alcanzó también un importante papel dentro del Nuevo Movimiento Zapatista (Leyva, 1999). ${ }^{2}$

Con ser paradigmáticos, los acontecimientos que caracterizan la vida político-electoral de Nicolás Ruiz no sólo se han visto marcados por el decidido apoyo al EZLN o al PRD. Hay también toda una serie de prácticas y eventos que configuran un panorama complejo, dentro de los que destacan la embestida gubernamental contra el municipio una vez que éste retira su apoyo al PRI, así como varias decisiones de la asamblea de comuneros, tales como la conformación de un consejo municipal autónomo en 1995, el abstencionismo electoral aceptado, el abstencionismo electoral castigado, el rechazo a la instalación de casillas en diferentes comicios, el control sobre la participación de las mujeres y la negativa a dar capacidad alguna de expresión política a la minoría priista subsistente. 3 El mantener su apoyo al PRI supuso, para aquellos hombres que así lo decidieron, y por ende para sus familias, la pérdida de sus derechos comunales en 1998. Desde entonces, este grupo puede votar -o no hacerlo-, pero su opción partidaria no tiene traducción alguna en la designación de los representantes municipales. La situación particular que vive esta minoría se adereza con el ostracismo social, un castigo que la propia asamblea añadió de manera explícita a la decisión de privarla de sus derechos agrarios, y que, al menos durante los primeros cinco años posteriores a su adopción, contó con amplio respaldo en el resto de los habitantes del pueblo. Es de destacar cómo todas las decisiones señaladas se toman por "usos y costumbres", tal y como refieren de manera reiterada y pública los portavoces masculinos del municipio. Nos encontramos así con un término que evoca, polémicamente si seguimos el ejemplo de Nicolás, los derechos de los pueblos indios y la propia cuestión de la comunidad misma.

Sin duda, existen diferentes maneras de usar el término "comunidad" - o "pueblo"-, así como de observar a ésta y registrarla etnográficamente (cfr. Viqueira, 2002). En mi análisis mostraré cómo los hombres y las mujeres del municipio que estudio pueden tener, a su vez, ideas, cambiantes en el tiempo, de lo que es la "comunidad", incluido el hecho de empezar a autoadscribirse a ella desde la perspectiva propia de contemplarse a sí mismos como indígenas y reivindicarlo ante el Estado nacional y la Organización Internacional del Trabajo (OIT).

En este artículo analizo las dinámicas locales de Nicolás Ruiz en el ámbito político-electoral de las últimas décadas. En el centro de dicho análisis está la asamblea de comuneros en perspectiva histórica, instancia máxima de toma de decisiones que ha definido la vida política municipal. Las consecuencias de varias de sus decisiones recientes retrotraen algunas características de la "comunidad revolucionaria institucional” (Rus, 1995 [1995]), como la unanimidad y el consenso políticos detrás de los cuales se encuentran prácticas no democráticas. Comienzo así con la exposición de Rus sobre la comunidad revolucionaria institucional y las formas en que este modelo ha 
sido aplicado a otros estudios políticos de Chiapas. Después observo que, en términos del apoyo al PRI, Nicolás Ruiz sigue un curso similar al de otros municipios del distrito electoral al que pertenece, sin dejar de mencionar los momentos excepcionales en que esta hegemonía se rompe en Totolapa y Chiapilla. En este mismo apartado referente a las décadas de 1970 y 1980 es relevante la forma en que en Nicolás se resuelven los conflictos (si bien no siempre es explicitado en la información de archivo se deduce que en ello la asamblea de comuneros juega un papel central), así como también el hecho de que los mismos no se traducen en la búsqueda de opciones diferentes al PRI. Los últimos apartados refieren las transformaciones político-electorales que han tenido lugar en el municipio desde los años noventa que, como sostengo, son fuertemente contenidos por la asamblea de comuneros. Con todo lo anterior, Nicolás Ruiz resulta ser un caso paradigmático de las transformaciones políticas profundas que empezaron a vivir comunidades y municipios habituados a apoyar al PRI y a los gobiernos estatales. Sin embargo, Nicolás no es sólo un municipio donde los elementos democratizadores se manifiestan, sino el caso de una población mayoritaria con reivindicaciones frente al gobierno local y el Estado nacional, lo que podría leerse en términos de "ciudadanía étnica” (Leyva, véase este volumen), al tiempo que la asamblea de comuneros impone restricciones internas (Kymlicka, 1996 [1995]) que limitan o anulan los derechos comunales y los derechos políticos de sus habitantes.

La comunidad revolucionaria institucional

"Comunidad revolucionaria institucional" es un término acuñado por Jan Rus (1994 [1995]) para caracterizar la situación sociopolítica de las comunidades indígenas de los Altos durante el predominio del PRI. ${ }^{4}$ Con él describe el proceso y el resultado de las políticas federales y estatales, desde la época de Lázaro Cárdenas (1936-1940), con las que se controlaba a la población indígena. A cambio de tal control los indígenas recibieron beneficios no despreciables, como la expropiación de fincas en manos de ladinos, la repartición de tierras y mejores condiciones de trabajo, así como, desde otro orden, la incorporación de las mujeres a la educación formal. Esos efectos democratizantes derivaron en expresiones de descontento popular, debido a las características autoritarias y verticales también existentes en el mismo proceso que empezaron a manifestarse en los años setenta. Los documentos del Archivo Histórico del Palacio Legislativo (AHPL), en Tuxtla Gutiérrez, Chiapas, me muestran que tal aseveración coincide en algunos lugares con el dato de la aparición de oposiciones al PRI que, de alguna manera, comenzaron a quebrar políticamente la comunidad revolucionaria institucional existente en las regiones.

Al mismo tiempo que en el marco de ese modelo de "comunidad" se confirió a los indígenas nuevos derechos, se construyó una forma más estrecha de dominación: los cardenistas y sus sucesores se inmiscuyeron en las comunidades indígenas, sustituyeron a sus líderes, reorganizaron los gobiernos, crearon nuevos puestos para tratar asuntos laborales y agrarios. Los escribanos y maestros bilingües se convirtieron así en los mediadores por excelencia, en las zonas indígenas, entre el Estado y las comunidades. El resultado de todo ese proceso fue la incrustación (eficiente) de las estructuras del PRI, así como de los gobiernos ligados a éste, en las comunidades indígenas. De aquí el nombre que Jan Rus ha dado a todo ese proceso: comunidad revolucionaria institucional. 
Dicho término ha sido empleado en algunos estudios. En su análisis histórico-político, Neil Harvey (2000 [1998]) plantea que no todas las comunidades fueron transformadas por el Estado y el partido en el grado en que ocurrió en San Juan Chamula, el principal municipio sobre el que Rus basa su análisis. En Venustiano Carranza, los ancianos o principales fueron sustituidos por un nuevo cuerpo de autoridades erigidas con la reforma agraria en los años treinta, es decir, por el comisariado de bienes comunales. Pese a que el Estado y el partido se incrustaron también en la vida comunitaria de Carranza - la estructura de autoridad comunal fue incorporada al último- ese municipio no se convirtió en la comunidad revolucionaria institucional de los Altos:

en este caso las relaciones con las elites ladinas estaban más estrechamente vinculadas a las disputas por la tierra que en San Juan Chamula. Ello significaba que los nuevos y más jóvenes líderes sólo podían establecer su legitimidad recuperando las tierras comunales (Harvey, 2000 [1998]: 79).

Otra experiencia recogida por Harvey es la de los colonizadores indígenas en la Selva Lacandona, donde la débil presencia del Estado posibilitó a otras instituciones realizar un trabajo organizativo más independiente. Así empezó a hacerlo la Diócesis de San Cristóbal de las Casas, bajo el obispado de Samuel Ruiz García (1960-2000), a través de la catequesis de integración que promovía una activa participación de la gente en las comunidades. De manera que, según Harvey, a diferencia del sistema jerárquico de puestos civiles y religiosos en Chamula, en estos ejidos de la Selva las formas de organización fueron más horizontales. ${ }^{5}$

A su vez, Willibald Sonnleitner (2001) usa la categoría de comunidad revolucionaria institucional en el sentido de la hegemonía político-electoral del PRI, una dimensión presupuesta en el análisis de Rus. Para ver esta comunidad revolucionaria institucional en un sentido electoral, hay que retomar algunas cifras disponibles desde 1976 (Guillén, 1998) que revelan a Chiapas como un bastión tradicional del PRI, una de las reservas de votos más importante con que dicho partido contaba en el ámbito federal. ${ }^{6} \mathrm{Si}$ bajamos al ámbito local, decenas de municipios en el estado son ilustrativos de tal situación. Entre 1979 y 1988, en más de veinte de ellos el fenómeno de la completa unanimidad electoral priista estuvo presente: Altamirano, Amatenango del Valle, Chalchihuitán, Chamula, Chanal, Larráinzar, Mitontic, Tenejapa y Oxchuc; así como también en Angel Albino Corzo, Berriozábal, Chicomuselo, Coapilla, Ixtapangojoya, La Libertad, Nicolás Ruiz, Pantepec, Pichucalco, Siltepec, Socoltenango, Sunuapa, Tapalapa y Venustiano Carranza.

Esta unanimidad electoral previa a 1991 - según documentos del AHPL - no era producto de un fraude electoral per se; además, las cifras que corresponden a las oposiciones al PRI constituyen en muchos casos una auténtica expresión de problemas sociales y políticos. En efecto, la unanimidad priista fue cuestionada varias veces antes de la gran debacle del PRI en 1988 en el ámbito nacional, así como de la que se inició en 1991 en el estado. Esto quiere decir que si hubo fraude como efectivamente se muestra en algunos documentos gracias a la 
InÉs CASTRO ApREZA

protesta que interponen los actores políticos ante el congreso local, no se llevaba a cabo al punto de desconocer completamente a la oposición. $^{7}$

Así, desde 1991, las cifras electorales en diferentes regiones revelan de manera generalizada preferencias políticas diferentes al PRI. Es ilustrativo que, en el ámbito municipal, en las elecciones de ese año, en 51 de los 111 ayuntamientos del estado el total de personas $(100 \%)$ que votó lo hizo por el PRI; ningún otro partido político recibió voto alguno. Cuatro años después, en 1995, el total de votantes lo hizo por un solo partido político tan sólo en seis municipios: San Juan Chamula, Ixhuatán, Ixtapangajoya, Mitontic y Sunuapa, donde el PRI fue ganador, y en Nicolás Ruiz, donde el vencedor fue el PRD. En 1998, sólo en Chalchihuitán y Larráinzar el total de votos favoreció exclusivamente al PRI; $y$, finalmente, en el proceso electoral de 2001 no encontramos ningún ayuntamiento en el que se vote por un solo partido político.

La unanimidad electoral es, definitivamente, cosa del pasado. La situación de Nicolás Ruiz, no obstante, es sui generis, ya que pese a la existencia de diversas preferencias partidarias no se permite la expresión sino de una sola.

Ruptura de la hegemonía y búsqueda de alternativas

El Cuadro I nos muestra la votación municipal previa a 1991 de los municipios que componen el Distrito IV, al cual pertenece Nicolás Ruiz. El panorama que presenta es un buen ejemplo de la unanimidad electoral priista, pero también de la presencia clara, si bien esporádica, de la oposición política, es decir, de la búsqueda de alternativas por parte de los habitantes.
Cuadro I. Elecciones en los municipios del distrito IV de Chiapas (1979-1988)

\begin{tabular}{|c|c|c|c|c|c|c|c|c|c|c|c|c|}
\hline \multirow{2}{*}{ Municipios } & \multicolumn{2}{|c|}{ P R } & \multicolumn{2}{c|}{ P } & \multicolumn{2}{c|}{ A } & \multicolumn{3}{|c|}{ Abstención } \\
\cline { 2 - 14 } & 1979 & 1982 & 1985 & 1988 & 1979 & 1982 & 1985 & 1988 & 1979 & 1982 & 1985 & 1988 \\
\hline Amatenango del Valle & 100 & 100 & 0 & 100 & 0 & 0 & 0 & 0 & 4 & 0 & 0 & 9 \\
\hline Chiapilla & 76 & 100 & 54 & 100 & 24 & 0 & 44 & 0 & 82 & 22 & 41 & 30 \\
\hline Nicolás Ruiz & 100 & 100 & 100 & 100 & 0 & 0 & 0 & 0 & 11 & 41 & 4 & 17 \\
\hline San Lucas & 100 & 100 & 100 & 94 & 0 & 0 & 0 & 0 & 9 & 17 & 27 & 70 \\
\hline Socoltenango & 100 & 100 & 100 & 100 & 0 & 0 & 0 & 0 & 21 & 0 & 0 & 23 \\
\hline Totolapa & 100 & 100 & 72 & 100 & 0 & 0 & 28 & 0 & 33 & 24 & 41 & 15 \\
\hline Venustiano Carranza & 100 & 100 & 100 & 100 & 0 & 0 & 0 & 0 & 47 & 7 & 21 & 39 \\
\hline
\end{tabular}

Fuente: elaboración propia con datos de Diana Guillén (1998).

En este panorama distrital en el que el PRI alcanza $100 \%$ de la votación en diferentes elecciones, el resultado electoral del PAN en Chiapilla (24\%), en 1979, tiene antecedentes políticos que explican la caída priista $(76 \%)$ y que nos revelan una de las vías por las cuales empezó a quebrarse la comunidad revolucionaria institucional. Desde principios del año de 1977, el síndico municipal y cinco regidores expresaron su inconformidad ante el Congreso del Estado por la nominación de presidentes municipales por parte del PRI sin que los dirigentes hubieran hecho un "análisis debido" en el proceso de selección para elegir a las mejores personas. Hacia fines del mismo año de 1977, el presidente municipal fue nuevamente objeto de críticas y censuras por parte de la población debido al encarcelamiento sin justificación alguna de dos profesores de la escuela primaria del lugar. ${ }^{8}$ Finalmente, en el proceso electoral de 1979, alrededor de treinta personas envían un oficio al gobernador del estado para señalar que el candidato triunfador del PRI tiene "malos antecedentes" y que se valió de artimañas para ganar la elección. Lo acusan de haber repartido, el mismo día de la votación y de común acuerdo con las autoridades salientes, las credenciales electorales a sus seguidores, negándoselas a otros.? 
El conflicto entre los seguidores del PAN y los afiliados al PRI tuvo continuidad. E1 primero de diciembre de 1985, el presidente del comité municipal del PAN envió un oficio al Congreso del Estado para denunciar el fraude electoral en los comicios realizados en ese mismo año. De las dos casillas instaladas en el municipio sólo en una pudieron estar presentes los representantes panistas y contabilizar 182 votos para el PRI y 588 para el PAN; en la otra fueron amenazados con machete en mano por el grupo priista. En esta última casilla el número de electores era de 270 , de manera que aun cuando en ella hubiese ganado el PRI no podía haberlo hecho en el ámbito municipal dado el resultado de la primera. El anuncio de un posible enfrentamiento si no se reconocía el triunfo del candidato panista no parece haberse confirmado, pero sí la persistencia de la rivalidad entre los dos grupos. ${ }^{10}$ Los priistas se agruparon en torno a la presidencia municipal, mientras que los panistas lo hicieron en el comisariado ejidal. Este modelo de posicionamiento en uno $u$ otro espacio pudo haber sido adoptado por los grupos enfrentados, contrarios entre sí, en otros lugares donde existían como tales y la disidencia podía acceder en algún grado a los canales de expresión existentes. En ese modelo, que empieza a cuestionar el de la comunidad revolucionaria institucional, si no había democratización electoral, en la medida en que no se permitía el triunfo de las oposiciones al PRI, sí existía una democratización política en el sentido de que diferentes espacios públicos de poder (de toma de decisiones) eran ocupados por distintos grupos, lo que, a la postre, abre mayores posibilidades a aquella primera.

En lo que hace a Totolapa, no existe documento al respecto en el AHPL, pero durante la etnografía realizada de las fiestas religiosas que celebra conjuntamente con Nicolás Ruiz, ${ }^{11}$ encontramos testimonios sobre el conflicto que se vivió en 1985 y que llevó a algunos habitantes a buscar opciones alternativas al PRI. El conflicto local, al igual que en Chiapilla, se tradujo en una votación importante para el PAN (28\%).

En este panorama regional, queda claro que Nicolás Ruiz no es un caso aislado de hegemonía priista, como tampoco lo será de la formación de una minoría disidente frente a una mayoría partidaria. Es también un caso sui generis porque, como se verá en las siguientes secciones, la asamblea de comuneros persiste en el modelo de la unanimidad electoral pese a la manifestación de opciones políticas distintas. Sin embargo, podría no ser extraño, ya que, en perspectiva histórica, se puede ver que Nicolás ha funcionado mediante el consenso sobrepuesto a la pluralidad de las expresiones.

Se puede ver lo anterior en la resolución de sus conflictos y en el hecho de que éstos no se hayan traducido en la búsqueda de opciones políticas distintas. A diferencia de sus vecinos en particular de Venustiano Carranza (Harvey, 2000 [1998]), el municipio vivió un estado de paz social hasta principios de los años noventa, que se refleja por igual en sus cifras electorales (veáse Cuadro I), documentos de archivo y testimonios de los habitantes (excepción hecha de los momentos en que los comuneros, en la lucha por la tierra, se enfrentaron con sus vecinos, cfr. Speed, 2004). La gente se veía a sí misma como quien goza de una "tranquilidad envidiable". En su informe de gobierno al Congreso del Estado, en 1977, el presidente municipal Donaciano Juárez Gómez destacó en su "lacónico" escrito como él mismo dice de la única página presentada que entre los aspectos favorables estaban la conformidad del pueblo, el apoyo decidido de las mayorías 
y el deseo de trabajar unidos con la autoridad entrante. ${ }^{12}$ Esta conformidad y unión se quebraría con respecto a quien ocupaba entonces el cargo de autoridad municipal, pero las motivaciones originales de la ruptura revelan, paradójicamente, el mismo estado de paz social. En 1978 el pueblo constituido en Asamblea General Extraordinaria "desconoció" al presidente municipal y exigió su renuncia. ${ }^{13} \mathrm{El}$ motivo fue que el presidente obligaba a ocho hombres a cumplir servicios como policías municipales más allá del período convenido. ${ }^{14}$ El presidente había impuesto cárcel y multa por desobediencia a esos hombres, quienes, al suscitarse el conflicto, contaron con el apoyo de muchas personas. En su denuncia al congreso del estado, ellos dicen:

es el caso que desde que empezamos a dar nuestros servicios hemos venido trabajando bien, dando nuestro servicio de ronda cada sábado, es el caso que ya fastidiados de tanto dar servicios inoficiosos, en virtud de que en este pueblo no bay ningún desorden, alegamos nuestros derechos diciéndole al presidente que ya no estábamos dispuestos a dar dicho servicio (NR/4 junio 1977/AHPL, cursivas mías).

Este y otros problemas que ocurrieron reflejaban ciertamente una forma de funcionamiento particular del municipio porque ya se sanciona la desobediencia interna y se censura el hecho de recurrir a instancias externas en la búsqueda de soluciones a los conflictos. El otro caso fue el de nueve comuneros y sus familias expulsados del municipio en 1979; previamente, los privaron de sus parcelas y sus casas debido a la desobediencia respecto de la orden de no poner alambres de púas en sus parcelas, considerada como desacatamiento de la voluntad general. ${ }^{15}$ Finalmente, se sabe de la situación de una mujer que tenía problemas personales y familiares con su esposo quien, al agotar ella las vías internas para resolverlos sin tener éxito alguno, intentó recurrir al juez municipal de Venustiano Carranza. Frente a esto, fue expulsada de Nicolás Ruiz y privada de sus bienes. Más allá del drama personal y familiar de los afectados, los casos no descartan el carácter "pacífico" del municipio en la medida en que hubo un supuesto consenso entre la población en contra de los mismos infractores. Otro asunto, de no menor importancia para la historia política local, es cómo los habitantes se ven a sí mismos retrospectivamente. Más de veinte años después, en el contexto de fuertes y diversos conflictos internos, al rememorar aquellas expulsiones algunas personas no parecían ya convencidas de las drásticas medidas. Desde el punto de vista político-electoral, no obstante, lo decisivo es que ese tipo de conflictos no se tradujo en Nicolás en búsquedas de sus habitantes de agrupaciones políticas diferentes al PRI. Fue hasta 1994 cuando la población buscó nuevos caminos.

La asamblea de comuneros y las transformaciones políticas

En el AHPL, los documentos municipales con reivindicaciones políticas y electorales empiezan a ser más frecuentes en los años noventa. Ello podría indicarnos la importancia creciente de los procesos electorales, las disputas por el poder municipal y del voto ciudadano en sus diferentes expresiones, ${ }^{16}$ tanto como el conocimiento de los actores locales respecto de las autoridades estatales en la materia (el congreso local en particular) a las cuales acudir en caso de conflictos e inconformidades. Electoral y políticamente, 1994 es un año importante tanto porque posibilita abundar en el debate abierto en 1992 en torno a los derechos de los pueblos indios como por el interés que los procesos 
electorales empiezan a despertar en la ciudadanía del estado (Viqueira y Sonnleitner, 2000; Gómez Tagle y Valdés Vega, 1997). En ese año se alentó un inusitado proceso organizativo en torno a la elección estatal para elegir gobernador; será entonces el único momento en que el EZLN llame a votar. En 1995 y 2000, de manera explícita, el EZLN hizo llamados a la abstención e inclusive se atribuye a sus bases de apoyo la quema de casillas en algunos lugares. En 1995, Nicolás Ruiz muestra un nivel de abstención de casi 50\%, que no vuelve a presentarse en los años subsecuentes, por lo menos en esa magnitud (en el año 2000, alrededor de setenta personas no votaron, por lo que se les impuso una multa de cincuenta pesos a cada una). La única explicación posible del fenómeno social en 1995 es que los abstencionistas eran parte de las bases de apoyo del EZLN, que acataron la orden de la organización -como la llaman-, y que la misma fue respetada y seguramente acordada en la asamblea de comuneros.

Cuadro II. Elecciones municipales y federales en Nicolás Ruiz

\begin{tabular}{|c|c|c|c|c|c|}
\hline Año & Lista Nominal & PRI & PRD & PAN & Votos válidos \\
\hline 1991 & 1,173 & 1,021 & 0 & 0 & 1,021 \\
\hline 1994 & 1,363 & 0 & 1,139 & 0 & 1,139 \\
\hline 1995 & 1,425 & 0 & 720 & 0 & 720 \\
\hline 1997 & 1,600 & 0 & 0 & 0 & 0 \\
\hline 1998 & 1,653 & 326 & 1,055 & 0 & 1,381 \\
\hline 2000 & & 260 & 1,137 & 0 & 1,431 \\
\hline 2001 & & 278 & 1,219 & 0 & 1,497 \\
\hline
\end{tabular}

Fuente: elaboración propia con datos del Instituto Federal Electoral.

Como lo muestra el Cuadro II, las firmes decisiones obtenidas en la asamblea se plasman en la monotonía de las cifras electorales; de hecho, el municipio podría no concitar interés académico alguno si nos guiásemos por éstas. Nicolás Ruiz es un solo espacio geográfico, es decir, no está conformado por comunidades como el resto de los municipios en Chiapas; en él tiene actualmente tan sólo una sección electoral (la número 814) compuesta por tres casillas (una básica y dos contiguas). Por ello podría parecer poco o nada interesante desde el punto de vista político-electoral. Sin embargo, algunos de los indicadores más importantes de la democratización han estado presentes en la historia política municipal; detrás de las cifras se desarrollan fenómenos que éstas no alcanzan a develar, en parte debido al mecanismo asambleario que los contiene. La importancia que el voto ha adquirido entre la población como algunas mujeres lo rememoran al referir que, antes de 1994, eran sus esposos quienes se dirigían a las urnas y mostraban las credenciales de elector propias y las de ellas, la presencia de diversos partidos políticos y la eventual (o imposible) alternancia de éstos, la gestación de minorías, la percepción social sobre la necesidad de que haya dos candidatos y no uno en la asamblea de comuneros para la presidencia municipal, así como la mayor participación política de las mujeres en los primeros años posteriores al 94 son cuestiones que muestran la densidad de la democratización interna. En conjunto, hacen visibles las transformaciones políticas más significativas del municipio, ${ }^{17}$ paralelas al cambio de partido político.

¿Qué hizo posible que el PRI pasase del 100\% de los votos en 1991 al 0\% en 1994? ¿Qué ocurre para que, esta vez, los habitantes de Nicolás sí busquen alternativas políticas? Una respuesta está en la favorable coyuntura estatal abierta en 1994, pero también en los factores que anunciaban la inconformidad con el estado de cosas. Uno de 
tales factores fue el de las impopulares medidas tomadas por el gobierno del estado sobre la disposición de los recursos naturales. En el contexto internacional de mayor preocupación por el medio ambiente y la conservación de los recursos naturales, el gobierno federal de Carlos Salinas de Gortari (1988-1994) impulsó leyes y reglamentos en los estados. La política forestal consistió, básicamente, en restringir los permisos de explotación, para lo cual se creó la Coordinación Forestal del Estado de Chiapas, cuya función era imponer la veda forestal. El mayor problema para los campesinos fue el de las adiciones al Código Penal para tipificar delitos por daño al patrimonio ecológico, con penas de dos a diez años de prisión para quienes explotaran los recursos forestales sin autorización. Tales lineamientos no fueron bien recibidos por la población campesina de Nicolás debido a que ya no se permitía la tala de árboles sobre los montes, práctica seguida por ésta con el objeto de repartir terrenos cultivables entre la población masculina joven que contraía matrimonio. El incremento de la población conlleva mayor demanda de tierras $y$, como se sabe, no siempre es posible satisfacerla.

Otra política gubernamental que progresivamente alejó a los habitantes del PRI fue la falta de solución a las demandas de nuevas tierras y el reconocimiento de viejas (Speed, 2004). Con todo, el cambio o rejuego generacional es un elemento significativo en la búsqueda de alternativas políticas. Un grupo de comuneros varios de ellos jóvenes encabezó el cuestionamiento al orden existente en el que un pequeño número de hombres ("el grupo privilegiado", "el grupo de los 23”, como se los ha llamado) "manejaba" a la comunidad y tomaba siempre el mando de la presidencia municipal y de los bienes comunales. Esos comuneros, claramente, empezaron a cuestionar a la asamblea de comuneros pero no como una instancia de toma de decisiones, sino como un ámbito que era controlado por unos pocos. Entre la población se suele decir que fueron "nuestros abuelos" quienes heredaron esa forma de funcionamiento asamblearia y que así se ha hecho "siempre". En este decir popular que un agente externo escucha hay un cierto aire de "antigüedad", de tiempos remotos difícilmente descifrables o ubicables en el tiempo porque se trata claramente de una simbolización colectiva. Cuando, en 1998, la mayoría de la población empezó a utilizar el término usos y costumbres buscaba referirse precisamente al hecho de que la asamblea de comuneros, celebrada el último día de cada mes, es la instancia en que se toman las decisiones y ninguna de éstas fuera de dicho espacio es considerada posible, válida ni legítima. ${ }^{18} \mathrm{La}$ Ley Federal de la Reforma Agraria ha desempeñado un papel importante en la configuración de estas relaciones sociales comunitarias, debido al peso que se le ha otorgado a las deliberaciones y decisiones colectivas. La centralidad de la tierra en las comunidades indígenas y campesinas, la regularidad de la asamblea que deviene en un punto de referencia básico para la comunidad, tanto como la ascendencia patrilineal dominante, son factores importantes que, sin duda, han incidido en el hecho de que en esa institución se tomen decisiones que van más allá de los asuntos relativos a la tierra misma. Sea por una tradición milenaria, un mecanismo alimentado por políticas gubernamentales y métodos clientelares promovidos por el PRI durante décadas (como el de la comunidad revolucionaria institucional), y hasta una tradición reinventada en el contexto del levantamiento armado zapatista, o bien una 
mezcla de todo ello, en Nicolás se supone que el conjunto de los habitantes sigue siempre, debe seguir, un solo camino. Si alguien no asume lo que en la asamblea de comuneros se ha acordado, ello se toma como una violación a las decisiones de la comunidad, a las decisiones del pueblo. Tal ha sido la equivalencia semántica, cultural y política establecida entre lo que decide la asamblea de comuneros y lo que decide el pueblo, imagen ampliamente aceptada que, en cualquier caso, sufre importantes quiebres y rupturas en diferentes momentos.

En algún momento, precisamente, los cuestionadores del status quo descubrieron que la asamblea era manejada por el "grupo privilegiado", con lo que éste se apartaba de aquella remota y ancestral tradición. Por tanto, se entiende que en la protesta por el cambio, el deseo era hacer de la asamblea de comuneros una auténtica representación de voces, de toma de decisiones consensuada y de vía de expresión del pueblo, de la comunidad.

Una característica de esos comuneros críticos con el antiguo orden existente es que tenía más nexos sociales y políticos con el exterior o, por lo menos, había conseguido establecer nuevos y diferentes a los de la generación previa. Algunos de esos nexos se remontaban a dos décadas atrás, como lo muestra una nota del 29 de abril de 1983 en poder de la asociación civil Desarrollo Económico, Social de los Mexicanos Indígenas (Desmi, A.C.), si bien, valdría añadir, tampoco esos lazos se tradujeron entonces en una búsqueda de alternativas electorales:

Entregamos un crédito de 55 mil a un grupo de 12 personas de Nicolás Ruiz para apoyar una iniciativa de buscar alternativas de trabajo en la población que está pasando por una serie de problemas a partir de la problemática agraria con Flores Magón. El grupo ha reflexionado durante un tiempo con las hermanas religiosas, y piensan continuar. Tienen una posición crítica a toda la manipulación y a la injerencia del Cora en los asuntos (el Cora de Venustiano Carranza, JSS); pero se encuentran vencidos ante la intransigencia de sus compañeros manipulados por los líderes de la CNC. Aunque la CNC no les hace caso tampoco, ni siquiera cumplió el gobernador Juan Sabines en darles el crédito para comprar las tierras, una jugada que hicieron para que pelearan las tierras con Flores Magón. (....) Sería importante mantener esta relación, tienen las personas encargadas una experiencia de organización y ya actuaron organizadamente con otras comunidades del país a través de la CNPA. ${ }^{19}$

Si esos jóvenes tenían nexos con Desmi, guardaban también lazos con la Diócesis de San Cristóbal de Las Casas que les proporcionaban conocimiento nuevo, información y alternativas. Como se sabe, la información es un bien escaso en las comunidades y son los agentes externos, muchas veces, quienes llevan este recurso a grupos determinados. Cuando esta función la cumplen algunos agentes internos se trata de aquellos que sostienen más ligas con el exterior. En los espacios públicos de reflexión y acción formados por el personal diocesano, desde grupos pequeños que se reúnen habitualmente en los templos católicos de las comunidades hasta encuentros y foros realizados en la ciudad de San Cristóbal, se ha reflexionado sobre el acontecer político y la propia circunstancia sobre la base de la lectura y las enseñanzas de la Biblia. Estos espacios públicos de reflexión y acción no fueron ocupados por quienes tradicionalmente tenían cargos municipales y, por ende, poder y 
autoridad oficiales. Quienes han estado en dichos espacios han sido acaso con excepciones quienes carecían de tales posiciones de poder o quienes menos se beneficiaban de las mismas. A su vez, esos nuevos espacios públicos generan posiciones de representación que, si bien no inciden directa o inmediatamente en la toma de decisiones del cabildo o en las instancias comunitarias, tienen en el mediano y largo plazos un impacto en las relaciones de poder y, en algunos casos, en las relaciones de género internas. Es decir, inciden en la reestructuración comunitaria. De tal modo, esos espacios públicos han sido de alguna manera factores del cambio social y político, impulsores de las transformaciones políticas contemporáneas. Eso ocurrió en Nicolás Ruiz. Quienes empezaron a cuestionar el antiguo orden existente son parte del pueblo creyente, es decir, de la comunidad católica militante del territorio diocesano. Incluso algunos de estos jóvenes opositores empezaron igualmente el proceso organizativo de las bases zapatistas locales.

El resultado de los cambios municipales en un contexto estatal favorable fue la ruptura con el PRI en 1994 y la búsqueda de otros partidos. En un oficio dirigido a Juan José Rueda Aguilar, presidente de la Gran Comisión del Congreso del Estado, firmado por Félix Moreno González, a la sazón presidente municipal y uno de los históricos líderes locales del PRI, se comenta que a partir del 21 de marzo de 1994 tomaron posesión del predio Gran Poder, uno de los terrenos en histórica disputa. La acción fue organizada por el Partido del Frente Cardenista de Reconstrucción Nacional (PFCRN), que inicialmente apoyó a los comuneros. ${ }^{20} \mathrm{El}$ hecho de que el PRD, surgido de la experiencia política nacional de 1988, ya estaba perfilado como la principal oposición de izquierdas, contribuyó a que este partido fuese identificado como la mejor opción frente al PRI, con lo que los comuneros se alejaron del PFCRN.

No sólo la decisión de cambiar de partido se toma en la asamblea de comuneros; también aquí se realiza la misma elección del presidente municipal, ya que se define al candidato "único". Mientras tanto, en la jornada electoral la población vota por el elegido. Ciertamente, con antelación a este proceso donde se selecciona al candidato, en los espacios privados la gente empieza a hablar de las posibilidades que algunos comuneros tienen de serlo y, a medida que se acerca la fecha de la asamblea en la que tal evento ocurrirá, se sabe con alguna certeza quién será propuesto y electo. La decisión, en consecuencia, comienza a gestarse fuera de la misma asamblea en un marco en el que los grupos miden fuerzas y se produce cierta negociación implícita, aunque la gente suele considerar por lo menos frente al agente externo que es esa instancia suprema el ente decisorio. Resulta evidente, de todas maneras, que tal consenso aparente no excluye la inconformidad o el abierto desacuerdo respecto del candidato único, así como tampoco el hecho de sentirse o saberse más o menos representado con uno u otro de los posibles candidatos.

En un intento por visualizar el funcionamiento real de la asamblea de comuneros identifiqué dos grupos dentro de la mayoría de la población incluida en dicha instancia, y más allá de la auto representación de ésta como un todo homogéneo, a saber, el grupo hegemónico y el grupo disidente. Los he definido a partir de una variable, las relaciones de poder, y dos indicadores: la capacidad para acceder a cargos en la presidencia municipal y en los bienes comunales, así como de incidir en la toma de decisiones. Como intento sugerir con los nombres dados, el grupo hegemónico 
tiene más poder que el grupo disidente en ambos indicadores. A este último, con menos poder, lo llamo "disidente" por el hecho de que algunos de sus hombres y mujeres líderes han sido protagonistas de las rebeldías de 1994, tanto como de las que se expresaron entre 1999 y 2000 dentro de la mayoría. El grado de disidencia de tales líderes no ha llegado al punto de su "desconocimiento" en la asamblea de comuneros, aunque sí se les ha amenazado. En cualquier caso, el grupo hegemónico y el disidente tienen garantizada su representación política en las carteras de bienes comunales e igualmente se han visto representados electoralmente, de manera alternada, en los cargos del cabildo (sin abundar en las relaciones de género prevalecientes, es menester señalar que la representación política y comunal es exclusivamente masculina). La existencia tolerada del grupo disidente y sus posibilidades reales de verse representado constituyen un mecanismo de contención de mayores conflictos que pudiesen fraccionar de manera más evidente a Nicolás Ruiz, todo lo cual, notoriamente, pone de manifiesto el funcionamiento práctico de la asamblea y de los usos y costumbres, además de matizar la así denominada consensualidad.

En tal sentido, si los procesos electorales locales parecieran ser una formalidad, un mero trámite, constituyen el momento para definir internamente quién o quiénes tendrán un mayor acceso a los recursos materiales y simbólicos. Si el grupo hegemónico ha logrado hasta ahora un mejor posicionamiento tanto en la presidencia municipal como en los bienes comunales, el grupo disidente ha conquistado cargos que reflejan, cuando menos, su poder de negociación, su capacidad para hacerse saber internamente como un grupo con fuerza. En el momento culmen de los conflictos entre ambos grupos (en el año 2000), un miembro del disidente fue designado candidato a la presidencia municipal, lo que provocó malestar entre muchos dado que su cargo previo había sido el de chofer del cabildo. El favorito entre algunos comuneros era otro hombre del mismo grupo disidente, pero tenía una orden de aprehensión desde mayo de 1998, con lo que no podía figurar como candidato. Por tanto, la rigidez que podría traslucirse en la afirmación de que todo se decide por o en la asamblea de comuneros parece desmentirse, o cuando menos relativizarse, frente a este tipo de situaciones. Junto al azar, elemento presente en la política, el reconocimiento implícito de la existencia de por lo menos dos grupos puede entrar en juego para estabilizar la correlación de fuerzas y preservar así la "comunidad" y el "pueblo".

La comunidad y el pueblo, no obstante, cambian de sentido con el paso del tiempo. Si a principios de 1994, tales categorías incluían a toda la población, a medida que creció el conflicto con los priistas empezaron a significar la mayoría de hombres y mujeres; mientras que, a partir de 1999 cuando se pronunciaron las diferencias entre esa misma mayoría, los términos aludían a aquellos hombres y mujeres que acataban las decisiones de la asamblea de comuneros. El lenguaje y la práctica cotidianos reflejan bien las relaciones de poder internas, incluido el hecho de cómo realmente funciona la asamblea de comuneros: como en otros tantos lugares, dicha instancia se revela en diferentes momentos como un espacio de conflicto y negociación de fuerzas. La definición colectiva que busca incluir y excluir refleja finalmente la obediencia que, por parte de la población, esperan las autoridades y los grupos de poder locales respecto de sus decisiones. 
La "autonomía” municipal y el ataque del Estado

La búsqueda de alternativas político-electorales no deja a un lado el hecho de que, en algún momento, la población de Nicolás haya pensado en la posibilidad de funcionar sinpartidos, de hacerse independientes. Un halo de "autonomía", asociado sin duda al discurso zapatista, empezó a dibujarse en el imaginario de los habitantes.

En el municipio no hay más de un candidato a la presidencia, como señalé antes, y no se permiten las campañas políticas: ¿son necesarios los partidos ahí donde se funciona por usos y costumbres? La idea de independizarse de los partidos políticos, sin embargo, no prosperó dado que tanto la Ley Electoral del estado como el Código Federal de Instituciones y Procedimientos Electorales (COFIPE) señalan que serán las organizaciones partidistas las que postulen a los candidatos para los cargos de elección popular.

La opción por el PRD no se vivió de manera coercitiva, pese a todo, al menos por la mayoría de la población, pero también es verdad que esto no parece cambiar la percepción social respecto de los partidos. Cuando la gente habla del apoyo al PRD, suele hacerlo de manera pragmática, es decir, sin mayores convicciones político-ideológicas. Usan las siglas de un partido porque la ley así lo exige; se hace un uso instrumental del mismo, no se vota porque se le considere una alternativa de izquierda o porque represente el mejor proyecto político nacional o estatal. No es casual que precisamente en las elecciones que la población no ha votado sean aquéllas de carácter federal (1997 y 2003), es decir, cuando no se ve obligada a representarse por partido alguno para elegir a su presidente municipal. En su disputa con el gobierno estatal, primero, y con la minoría priista, después, las elecciones federales son coyunturas propicias que permiten o sirven a los comuneros para presionar al gobierno estatal por sus demandas de tierras. Nicolás Ruiz no participa en tales elecciones con el argumento de que el gobierno local no atiende sus demandas, con lo que, en una mezcla de pragmatismo y metáfora política, ratifican simultáneamente su "autonomía".

Son sobre todo los comuneros quienes refieren que el municipio es "autónomo". El término de autonomía se ha incorporado crecientemente al discurso de algunos grupos sociales y políticos, pero no por ello su significado es homogéneo, sino que también depende de varios factores, entre los que la historia y la experiencia propias desempeñan un papel importante. No es claro cómo realmente el EZLN está construyendo la autonomía en los territorios que gobierna, ya que, hasta ahora, existen pocos estudios con una base etnográfica que los respalde (Forbis, 2003; Mier y Terán, 2004; Van Der Haar, 2004). En cuanto a los comuneros el significado que dan a su autonomía puede leerse a través de las políticas diversas emprendidas localmente que reflejan una postura decantada a favor del EZLN, incluida la muy conocida "resistencia civil” frente al pago de la luz eléctrica que llevó a los habitantes a las primeras filas de la Asamblea Estatal de la Resistencia (ASER) conformada por varias organizaciones y municipios. Sin embargo, dichas políticas municipales también reflejan las contradicciones propias de quienes buscan tener las ventajas mayores de las situaciones como negociar con el gobierno estatal (a diferencia del EZLN que se ha negado a ello), recibir programas oficiales como PROCAMPO, aceptar los recursos públicos, negándose, simultáneamente, a participar en procesos electorales federales o a que se realicen registros como el censo de población y vivienda impulsado por el Instituto Nacional de Estadística, Geografía e Informática (INEGI). 
Sin ser finalmente uno de los municipios que el EZLN identificaba como "rebeldes" en sus comunicados de finales de 1994, Nicolás fue, no obstante, el único que impulsó la formación de un cabildo autónomo o consejo municipal autónomo en el año de 1995. La asamblea de comuneros decidió en algún momento no sumarse en términos estrictos a la autonomía zapatista, con lo que nunca ha dejado de recibir los ingresos de las arcas públicas que le corresponden al cabildo. Los comuneros se mueven así entre la "autonomía" entendida de modo sui generis y la necesidad de apegarse a normas y procesos nacionales.

En términos político-electorales, si no es un municipio autónomo en el sentido de abstenerse de participar en ellos, como hace el EZLN, tampoco los asume con libertad y pluralidad. El grupo que controlaba la comunidad y la asamblea fue finalmente desplazado del poder local, en 1995, es decir, de la presidencia municipal y de bienes comunales (dada la relevancia política local que este último espacio tiene en Nicolás). Ese grupo encabeza, en 1998, la disidencia política priista, pero no puede traducir su fuerza social en representación política municipal. Por ello mismo ha decidido no votar en algún comicio.

Pese a todo, esta prohibición de expresiones electorales distintas al PRD no ha borrado las diferencias políticas puestas de manifiesto. En un principio la minoría ligada al PRI parecía haberse sumado a la decisión de no apoyar más a este partido, pero la información de archivo muestra que nunca estuvo de acuerdo con esta medida. El 11 de febrero de 1994 el presidente municipal Félix Moreno envió un oficio a Javier López Moreno, gobernador del estado en turno, en el que demandaba apoyo para resolver asuntos agrarios, entre otras demandas. En el primer punto establecía:
(...) Que usted ya tiene en conocimiento que los comuneros de Nicolás Ruiz están interviniendo a una marcha en la ciudad de Tuxtla Gutiérrez, organizado por el Partido Frente Cardenista. De parte del presidente del PRI de este municipio en coordinación con el H. Ayuntamiento, pedimos todo el apoyo para así convencer a la gente que regrese a nuestro partido que es el PRI (AHPL, cursivas mías).

Es en el primer semestre de 1998 que "el grupo de los 23" expresó su abierta determinación de restituir su apoyo al PRI. Según la población mayoritaria de Nicolás ese mismo grupo aceptó la política gubernamental de 1992 de privatizar los ejidos y las tierras comunales, además de negarse a perder el poder del que había gozado durante mucho tiempo, razones ellas que llevaron a sus integrantes a seguir apoyando al PRI contraviniendo la decisión asamblearia de optar unánimemente por el PRD.

Entre abril y mayo de 1998, diez hombres decidieron instalar una oficina del PRI en el municipio, apoyados por la Secretaría de Gobierno y por el mismo PRI estatal. Ipso facto, la asamblea de comuneros tomó la decisión de quitar los derechos comunales -es decir, el derecho a poseer y trabajar las tierras-a seis de ellos, bajo el argumento de que violaron el acuerdo tomado. La prensa registró que más de cuatro mil habitantes del municipio, reunidos en asamblea general en el centro del pueblo, tomaron decisiones respecto de la situación de quienes violaran los acuerdos comunales. Los priistas detenidos fueron encerrados en la cárcel municipal, donde permanecieron tres días. Poco después, la asamblea de comuneros desconoció los derechos comunales de otras trece personas por similares razones. E1 
gobierno estatal habló entonces de la existencia de "grupos de radicales", mientras que la prensa calificó a Nicolás como un "santuario zapatistaperredista".

El Congreso del estado con mayoría priista retrasó la entrega de partidas presupuestales al ayuntamiento con el argumento de que existían atrasos en la presentación de la cuenta pública. La dirigencia estatal perredista respondió que la medida era una represalia porque el PRD no había firmado el Acuerdo Estatal por la Paz y la Reconciliación del gobernador Roberto Albores, que impulsó poco tiempo después de asumir el cargo en enero de 1998. El gobernador implementó el 3 de junio un operativo policiaco-militar en Nicolás que dejó un importante número de detenidos, encarcelados y robos, acción enmarcada en una serie de intervenciones que también afectaron a colonias indígenas en San Cristóbal de Las Casas y a tres municipios autónomos zapatistas (Castro, 2002). En esos días los habitantes de Nicolás señalaron ante la prensa que se convertirían en un "municipio autónomo", pero pronto la versión fue desmentida, esta vez públicamente:

\footnotetext{
Tampoco hemos mencionado que nos declaramos como un municipio autónomo. Cabe mencionar y aclarar que lo que bicimos referencia es que nos respeten nuestra autonomía que hemos venido respetando desde hace años, tal y como es nuestra forma de organizarnos como es de nombrar nuestras autoridades municipales a través de la Asamblea General (AHPL, 14 de mayo de 1998, cursivas mías).
}

Las negativas consecuencias de aquella intervención estatal pueden verse en que, hoy por hoy, persisten las medidas contra las familias que apoyan a partidos distintos al $\mathrm{PRD}$, aun cuando los comuneros que tienen lazos sanguíneos con la disidencia priista hace tiempo dejaron de estar de acuerdo con las drásticas políticas internas. Estos inconformes dentro de la mayoría recurren incluso al argumento de la "justicia” e injusticia, así como de pasajes bíblicos en los que "dios nos enseña cómo vivir", para explicar que ya no se debe seguir con aquellas medidas. Una vez más, el aparente consenso presenta quiebres y rupturas significativas, más allá de que éstas carezcan de canales de expresión internos.

En el año $2000,{ }^{21}$ el gobierno estatal propuso a los comuneros sostener algunas reuniones conjuntas en la capital del estado con miras a resolver el conflicto. Los comuneros respondieron que para hacer posible un diálogo, debería cumplir con el pliego petitorio que le habían presentado desde agosto de 1999. Entre las demandas estaban: 1) la cancelación de las órdenes de aprehensión que tenían varios comuneros; 2) la libertad de los comuneros procesados desde el operativo, así como del comunero arrestado por el asesinato de un integrante priista; 3) la devolución de los títulos primordiales que amparaban la propiedad de las tierras de la comunidad, robados el 3 de junio, es decir, del Tatabuelo, como lo llama la población, y del que Jan de Vos paleografió una parte $; 22$ ) la desintegración de Grupo Alianza Campesina (como se llamaron los priistas por un tiempo), creado, según los perredistas, con el propósito de fomentar confrontaciones y conflictos y 5) el respeto irrestricto de tradiciones, usos y costumbres por parte del gobierno del estado de Chiapas, de acuerdo con el artículo cuarto de la Constitución Política. 
Nicolás Ruiz: LA LUCHA CONTRA EL Estado Y LA

RESTRICCIÓN INTERNA DE DERECHOS

Usos y costumbres: la lucha contra el Estado y las restricciones internas

La asamblea de comuneros empezaba a hacer uso de las posibilidades que ofrecía esa adición al artículo cuarto constitucional. El 28 de enero de 1992 el gobierno mexicano había publicado en el Diario Oficial de la Federación el texto de un nuevo párrafo del artículo cuarto en el que se reconoce el carácter pluricultural de la nación mexicana y el compromiso de promover y proteger la cultura de los pueblos indígenas, así como garantizar el acceso de éstos a la jurisdicción del Estado.

Según la revisión llevada a cabo en los archivos, antes de los años noventa no se hacía en Nicolás referencia o invocación alguna a los usos y costumbres. El uso de tal concepto, por lo que hace estrictamente a dicho municipio, está claramente ligado al período comprendido entre 1998 y 2003. Localmente, el primer año se refiere a la crisis interna con el grupo minoritario de priistas. A nivel estatal, en el año de 1998 se estaba en el momento cumbre de la violencia gubernamental, así como de la violencia paramilitar: la masacre de Acteal había tenido lugar el 22 de diciembre de 1997. En marzo de 1999, Roberto Albores presentó la Ley de Derechos y Cultura Indígena del Estado de Chiapas, de su propia creación, que se supone recogía los Acuerdos de San Andrés y que recibió fuertes críticas en su momento. Obviamente, si el gobierno federal había rechazado la Ley Cocopa y las conversaciones de paz entre este actor y el EZLN se mantenían suspendidas, desde septiembre de 1996, la Ley Albores no podía concitar apoyos ni simpatías.

Paradójicamente, en el estado de Oaxaca, en junio de 1998, se aprobaba la Ley de Derechos de los Pueblos y Comunidades Indígenas del
Estado de Oaxaca; antes, en septiembre de 1995 se había publicado el "Diario de la Renovación de los Ayuntamientos en los Municipios de Elección por Usos y Costumbres" del Código de Instituciones Políticas y Procedimientos Electorales de Oaxaca, y, en octubre de 1997, había aparecido la nueva versión de la "Renovación de los Ayuntamientos en Municipios que Electoralmente se Rigen por Normas de Derecho Consuetudinario". Actualmente, 418 municipios de los 570 que tiene Oaxaca se rige electoralmente por el sistema de usos y costumbres.

Frente a tales experiencias de Oaxaca y Chiapas, las secciones Sureste e Istmo del Centro de Investigaciones y Estudios Superiores en Antropología Social (CIESAS) organizaron un foro, en noviembre de 1999, con el objeto de compararlas en términos de las experiencias indígenas, las autonomías, las legislaciones y el reconocimiento de usos y costumbres en los procesos electorales en el primer estado. En este foro se destacó que una de las figuras polémicas de la Ley Albores era el Juzgado de Paz y Conciliación Indígena, que, a juicio de la antropóloga norteamericana Jane Collier (en Pasquel y Sarmiento, 2001: 189-200) revelaba las diferencias entre cómo el gobierno estatal esperaba que funcionaran y cómo se comportaban, en realidad, los jueces zinacantecos (Zinacantán es el municipio que la autora analiza), es decir, reflejaba un contraste importante en la manera en que cada cual concebía el conflicto. Justo cuando la costumbre tiene cierto reconocimiento legal el Estado pareciera apropiársela. ${ }^{23}$

Un ambiente favorable a los Acuerdos de San Andrés - por lo menos entre diversos círculos en todo el país- y planteamientos académicos que apoyaban, de una u otra forma, los usos y costumbres o los mecanismos internos de 
InÉs CAStro Apreza

resolución de conflictos comunitarios: ese era el contexto en que en Nicolás Ruiz la mayoría de la población empezó a hablar de sus usos y costumbres y a defenderlos. Sin embargo, si en un nivel la asamblea de comuneros centra todo en dicha defensa, en otro sentido, en las comunicaciones públicas de ambos lados que guarda el AHPL han referido que el conflicto es agrario. Este hecho revela que la tierra - ahora también traducido políticamente como territoriosigue siendo el problema básico, el referente toral en la vida de las personas, y que los derechos comunales están por encima de cualquier otro. Por ello mismo, el conflicto entre priistas y perredistas ofrece otras tantas posibilidades de lectura, particularmente en lo que se refiere al tema de los derechos.

Derechos colectivos versus derechos individuales. El gobierno del estado trató de acusar a personas concretas del conflicto entre la mayoría de la población y el grupo de priistas, ello le facilitaba la tarea de castigar individualmente e intentar someter -en plural, en este caso- a la población perredista. Es la forma de funcionamiento del derecho positivo, el dominante en México. El gobierno nunca hizo referencia a que las decisiones tomadas provenían de la asamblea de comuneros, instancia que los gobiernos estatales habían reconocido en el pasado basándose en la ley agraria y que, con base en la misma, incluso habían aceptado y respaldado la práctica de la expulsión.

A su vez, "el pueblo de Nicolás Ruiz" —de esta manera se firmaban desplegados periodísticos en 1998- explicaba que a las primeras personas acusadas se las privó de sus derechos comunales. Los habitantes decían que no aceptarían ninguna intromisión por parte de la Secretaría de Gobierno, ya que la solución a los problemas se busca y se resuelve en las asambleas idóneas. La explicación que dieron fue que al grupo minoritario no se le privaba de sus derechos por pertenecer al PRI, si bien en la práctica el resultado era éste, con lo que no se reconocen los derechos políticos. La Secretaría de Gobierno, a su vez, expresó su interés en dar una solución al problema que se afrontaba en la comunidad "entre perredistas y priistas", si bien el discurso del gobierno del estado reflejado en la prensa era más directo:

un grupo de radicales ha desquiciado una vez más la normalidad, con un criterio sumamente primitivo (sic) como son los usos y costumbres, pero éstos no pueden existir en contra de las leyes y las normas elementales de convivencia humana.

Desde que se iniciaron las negociaciones entre el gobierno estatal y las autoridades comunales y municipales, el primero defendió los diferentes derechos del grupo priista.

A principios del año $2000-y$, posteriormente, durante la gestión gubernamental de Pablo Salazar Mendiguchía (2000-2006) - los priistas empezaron a plantear sus demandas en varias direcciones. $\mathrm{La}$ principal ha sido la restitución de las doscientas cincuenta y tres hectáreas de las que fueron despojados el 15 de mayo de 1998; el deslinde de la parte proporcional que les corresponde de los terrenos comunales a 226 jefes de familia; la participación de los dos regidores plurinominales del PRI en el ayuntamiento y la aprehensión de dos de los tres responsables del asesinato de Narciso López Díaz, el candidato presidencial priista para las elecciones de 1998. ${ }^{24}$

En tal panorama, pareciera que se defendiesen, irresolublemente, derechos colectivos por un lado y derechos individuales por otro, discursos constrastantes que en la academia 
fueron leídos desde la perspectiva del discurso globalizado de los derechos humanos y el efecto prísmico de éstos a partir de las posiciones que los actores detentan en el conflicto político y armado de Chiapas ( $f r$. Leyva y Speed, 2001). El contexto político favorecía la idea de que el mecanismo de los usos y costumbres era un recurso legítimo de los pueblos indios. En ese momento no importaba lo que por el término de usos y costumbres se entendía ni si el municipio de Nicolás era o no indígena y en cuáles sentidos. La antropóloga norteamericana Shannon Speed (2004), estudiosa y conocedora del municipio, habla de la recuperación de la identidad indígena en Nicolás; en mi etnografía realizada deduzco que, en particular, son algunos hombres y algunas mujeres quienes han puesto de relevancia este último dato en el argumento de su defensa de los usos y costumbres, a saber, que ellos son indigenas. Tales hombres y tales mujeres son sobre todo los más cercanos al EZLN, inclusive constituyen en algunos casos sus bases de apoyo.

Si desde el Convenio 169 de la Organización Internacional del Trabajo la autoidentificación como pueblo indígena es un criterio central para la definición y el reconocimiento mismos, agregaría la necesidad de que, en el plano político, también se rescatase la distinción entre las protecciones externas que los pueblos usan frente a los poderes estatales y gubernamentales, por un lado, y las restricciones internas (Kymlicka, 1996 [1995]) a las que recurren los mismos pueblos para impedir un presunto desmembramiento de la comunidad, por otro. Desde esta perspectiva, tal vez quedaría clara no sólo la trascendencia de este tipo de luchas frente al Estado, sino también que los derechos humanos de la minoría priista han sido anulados en todo este tiempo de conflicto.
Los derechos politicos y los derechos agrarios. Es posible que la participación y la representación político-electoral haya estado, por lo menos durante algún tiempo, estrechamente ligada a la posesión de la tierra. Sólo la investigación histórica podría revelárnoslo. A partir del análisis de algunos casos, es claro que la decisión tomada en la asamblea para elegir al candidato a ocupar el cargo de presidente municipal no fue en el pasado algo exclusivo de Nicolás, en virtud de que en las asambleas ejidales y comunales solía nombrarse a los integrantes de los comités seccionales y municipales del PRI. ${ }^{25}$ Cuando la formación de grupos diversos y contrapuestos es cada vez más palmaria y, sobre todo, cuando éstos buscan la representatividad político-electoral, ese mecanismo asambleario deja de ser funcional, una avasalladora realidad histórica que afrontó San Juan Chamula, el prototipo de la comunidad revolucionaria institucional, de la hegemonía político-electoral del PRI, de las expulsiones indígenas y de la defensa y preservación de los usos y costumbres.

Ilustrativo de este conflicto es el hecho de que "el grupo privilegiado" de Nicolás levantara la bandera liberal del sufragio libre y efectivo cuando el procedimiento asambleario no le favorecía más. En un primer momento, el apoyo de Albores Guillén fue relativamente útil para sentirse por lo menos protegidos; al pasar los años, y de cara a gobiernos perredistas municipales sucesivos, así como de otro gobierno estatal surgido en el año 2000 de una alianza de partidos políticos como alternativa al PRI, los priistas no cedieron en su postura. Han amparado sus argumentos en los derechos políticos asentados en la Constitución Política: 
(...) al despojarnos de nuestras parcelas sin ninguna orden judicial sino que fueron invadidas por los comuneros perredistas con la única consigna de que nosotros pertenecemos al PRI, ya que la realidad es de que no estamos de acuerdo con sus ideologías de no respetar las leyes y el gobierno y como consecuencia el estado de derecho, del cual se nos está violando nuestras garantías consagradas en los artículos 14 y 16 constitucionales (AHPL, 17 de febrero de 2000). ${ }^{26}$

Primero unidos y después divididos en grupos, e inclusive en distintos partidos, los ex comuneros priistas han buscado primordialmente la recuperación de sus tierras, recurriendo como sus rivales lugareños a distintas normatividades. Toda resistencia puede agotarse después de algún tiempo, máxime cuando no se tiene beneficio alguno. Los priistas están ya en el punto del agotamiento y de la división desde hace tiempo. La mayoría de ellos (y de los que se sumaron al Partido del Trabajo) no ha abandonado el municipio; algunos han emigrado a Tuxtla Gutiérrez. En el marco de sus negociaciones iniciales con el gobierno de Pablo Salazar, consiguieron en otros lugares parcelas para cultivar. Unos más, radicados aun en el municipio, se dedican a la albañilería. Permanecer en el lugar en estas condiciones, es decir, sin tierra, sin participar en la asamblea, por un tiempo impedidos de establecer relaciones sociales con sus propios familiares, supone un estado de segregación y ostracismo difícilmente sostenible. No se van quizá porque esperan recuperar algún día las tierras perdidas, el único o el principal medio de vida que conocen los adultos. Permanecer en el municipio posibilita al menos conservar la casa propia y los animales, pero en el fondo no saben ni imaginan cómo vivir en otro sitio. Tal vez es el peso del arraigo a los bienes escasos que se poseen y, en particular, al principal derecho que se ha conocido y por el que se luchado durante décadas desde diferentes trincheras la gente del campo: el derecho a la tierra.

\section{Reflexiones finales}

Por medio de la revitalización de la asamblea de comuneros, a partir de 1994, se logró establecer una nueva comunidad formada por aquella mayoría de la población que acata las decisiones emanadas de tal instancia (sea por convencimiento real, costumbre o temor a represalias) y con la exclusión de las minorías políticas. La inexistencia de un partido oficial (en el viejo sentido) y un Estado que se incrusta en la vida comunitaria nos lleva a desechar el término de comunidad revolucionaria institucional para caracterizar a Nicolás. Dicha comunidad existe, si acaso, en el sentido de que se funciona, bajo mandato y presión, para apoyar a un solo partido político, acallando o excluyendo las voces disidentes.

Desde la perspectiva de modelos analíticos más recientes, podemos establecer que Nicolás Ruiz ha pasado de una forma de comunidad revolucionaria institucional, hasta principios de los años noventa, a otra caracterizada por un pluralismo político y electoral fuertemente contenido bajo grandes presiones y abiertas amenazas. Acaso sea éste una nueva forma de comunidad institucionalizada que, por lo visto, no termina de concretarse en la búsqueda y conquista de una "ciudadanía étnica" y tampoco acepta la expresión de los derechos políticos. Puede tratarse de una justificada lucha contra el Estado, pero que se mezcla con una no convincente política restrictiva interna de derechos. 


Notas
1 "Sandiegueros" es el gentilicio de los habitantes de
Nicolás Ruiz. El antiguo nombre del municipio fue
San Diego La Reforma, el cual todavía suele escucharse
entre la gente mayor.
2 Xóchitl Leyva (1999: 58) define en estos términos al

Nuevo Movimiento Zapatista: es el "frente amplio de alianzas y coaliciones surgido después del 1 de enero de 1994 a partir de la convergencia de líderes políticos, de representantes de organismos internacionales y de viejas y nuevas organizaciones populares. El NMZ es una especie de red política en movimiento que sintetiza y reelabora experiencias pasadas y presentes de lucha popular, de ahí su carácter de "nuevo".

3 La situación de las mujeres, que lleva a los conflictos entre la misma población mayoritaria manifestados abiertamente en el año 2000 , no es abordado en este artículo, entre otras razones porque no incidió directamente en el ámbito político-electoral.

${ }^{4}$ Para explicar el proceso de la comunidad revolucionaria institucional, Jan Rus habla de la formación del Departamento de Protección Indígena y del Sindicato de Trabajadores Indígenas en 1936, a cuyo frente estuvo Erasto Urbina; la formación del Instituto Nacional Indigenista en 1948 y del Centro Coordinador TzotzilTzeltal en los Altos, dependiente del anterior; de las transformaciones contrario sensu de aquellas primeras medidas, a partir de los años cuarenta, tales como el intento de desaparecer el Sindicato y de revertir la política de confiscación de tierras a la clase pudiente; así como el fortalecimiento de la posición económica de los escribanos de acuerdo a "normas capitalistas".

${ }^{5}$ Algunos indicadores a este respecto son los siguientes: los ancianos no eran los únicos que podían ascender a los cargos más altos, casi cuarenta por ciento de los pobladores ocupaban cargos y las asambleas comunitarias se convirtieron en el centro de la toma de decisiones.

${ }^{6}$ Algunos indicadores al respecto son ilustrativos. En las elecciones de 1976 formó parte del grupo de doce estados en los que el PRI obtuvo más del $95 \%$ de la votación; en 1982, fue uno de los tres en los que ese partido alcanzó $90 \%$ o más de la votación (Chiapas, 90\%; Quintana Roo, 94\%; Tabasco, 91\%). Y mientras en el proceso electoral de 1988 había ya nueve estados que presentaban resultados menores al 50\% para el PRI, que representaban el culmen de un proceso de manifestación de oposiciones al priismo, Chiapas fue el estado que aportó el mayor porcentaje de votación a este partido político $(89.8 \%, 601786$ votos) (Viqueira y Sonnleitner, 2000: 113).

${ }^{7}$ Como sostiene Juan Molinar Horcasitas (1991: 9), estudioso de las elecciones y actual funcionario panista, la estadística sobre votos de la oposición es relativamente más confiable que la estadística sobre votos del PRI, ya que era más fácil agregar votos a este último que quitárselos a la oposición.

${ }^{8}$ Oficio dirigido al Capitán Albrajan, Jefe de Seguridad Pública, firman profesores detenidos, Villa de Chiapilla, 17 de noviembre de 1977, AHPL, Chiapilla/ C-14/1976-1979.

${ }^{9}$ Oficio dirigido al gobernador del estado, Villa de Chiapilla, noviembre 20 de 1979, AHPL, Chiapilla/C14/1976-1979.

${ }^{10} \mathrm{Puede}$ verse el oficio dirigido al General Absalón Castellanos, firmado por el presidente municipal, Totolapa, abril 3 de 1987, AHPL, Totolapa/C31/1985-1988. En este mismo oficio, el presidente municipal denuncia, extrañamente, que el secretario general municipal de la Confederación Nacional Campesina (CNC) "también es activista de Acción Nacional”. La CNC, como sabemos, ha estado históricamente asociada al PRI.

${ }^{11} \mathrm{La}$ etnografía de tales fiestas la llevé cabo con Ricardo Iglesias Dorta, quien hizo la videograbación de las mismas, durante el año de 2003. La etnografía incluyó el viaje a caballo de Nicolás Ruiz a Totolapa y viceversa, al lado de la Junta Vecinal del Templo Mayor de San Diego de Alcalá y las autoridades municipales. Estamos en deuda y agradecemos enormemente el apoyo de Don Abel, presidente de la Junta en aquel momento, quien nos brindo todo tipo de facilidades para hacer una etnografía rigurosa.

${ }^{12}$ Informe de Gobierno, Presidente Municipal Donaciano Juárez Gómez, Nicolás Ruiz, 1 de enero de 1977, AHPL, Nicolás Ruiz/C-16/1977-1979.

${ }^{13}$ Acta de Asamblea General Extraordinaria, Nicolás Ruiz, 28 de octubre de 1978, Archivo Histórico del Palacio Legislativo. Nicolás Ruiz/C-16/1977-1979. Véase también Acta de Cabildo del 11 de diciembre de 1978, AHPL, Nicolás Ruiz/c-16/1977-1979 y 
oficio dirigido a Donaciano Juárez Gómez, presidente municipal, firmado por la Comisión Permanente del H. Congreso del Estado, 4 de abril de 1978, AHPL, Nicolás Ruiz/c-16/1977-1979.

${ }^{14}$ Oficio dirigido al presidente del $\mathrm{H}$. Congreso del Estado, AHPL, Nicolás Ruiz/C-16/1977-1979.

${ }^{15}$ Oficio dirigido al Gobernador del Estado, 14 de febrero de 1979, AHPL, Nicolás Ruiz/C-16/1977-1979 y oficio de 9 de junio de 1980, Nicolás Ruiz/C-20/1980-1982.

${ }^{16} \mathrm{El}$ voto puede ser corporativo, clientelar, individual, más o menos conciente, pero que, en cualquier caso, es más importante que en el pasado.

${ }^{17} \mathrm{La}$ aparición y desarrollo de las minorías religiosas protestantes es otra de las transformaciones políticas en el municipio.

${ }^{18} \mathrm{Un}$ comunero es un hombre adulto, cabeza de familia, posesionario y usufructuario de las tierras comunales cultivables del municipio. La asamblea está formada por casi seiscientos comuneros, quienes deliberan sobre los asuntos relacionados con las tierras comunales y tienen ciertas obligaciones, tales como hacer trabajos diversos para el cuidado de las tierras y realizar cooperaciones para satisfacer distintas necesidades de la comunidad.

${ }^{19}$ Agradezco a Jorge Santiago Santiago, así como a todo el equipo de Desmi, el haberme proporcionado sus viejas notas y una entrevista larga para conocer el trabajo de intervención social realizado en Nicolás Ruiz en los años ochenta.

${ }^{20} \mathrm{AHPL}, 14$ de abril de 1994.

${ }^{21}$ Después del operativo, algunos problemas más enfrentaron a los comuneros con la minoría priista. Uno de ellos ocurrió a fines de 1999, cuando el grupo priista contrató a una empresa de maíz diferente a la que la Asamblea de Comuneros había acordado, con el objeto de vender la cosecha. Otro conflicto tuvo lugar el primero de marzo del año 2000, cuando el grupo de "los 23" y algunos "pisacaites" se posesionaron del predio El Reparo, ubicado a dos kilómetros de Nicolás Ruiz.

${ }^{22} \mathrm{Jan}$ de Vos sostiene que dicho documento no se trata de los títulos primordiales, aunque en el proceso de la reivindicación agraria así empezaron a ser interpretados por la población. Comunicación personal.

${ }^{23}$ Lourdes de León y Sergio Sarmiento (2001), coordinadores del Foro Sureste sobre Derechos Indígenas, siguiendo a
Jane Collier, dicen en la introducción de las ponencias publicadas que los juzgados de paz y conciliación indígena podrían tratarse de un espacio de apropiación del Estado sobre las prácticas tradicionales de los sistemas normativos indios.

${ }^{24}$ Oficio dirigido a Roberto Armando Albores Guillén, gobernador del estado, 17 de febrero de 2000, firmado por Félix Moreno, representante del Grupo Alianza Campesina, AHPL.

${ }^{25}$ Véase el oficio dirigido al General Absalón Castellanos Domínguez, firmado por el presidente municipal de Totolapa, abril 3 de 1987, AHPL, Totolapa/ C31/1985-1988.

${ }^{26}$ Véase también el oficio dirigido a Roberto Albores Guillén, gobernador del estado, del 4 de octubre de 1999, en el que el Grupo Alianza Campesina dice: somos "sabedores que existe una Constitución Política en nuestro país. Solicitamos con apego a la ley que se nos respete nuestra forma de organizar y respeto a nuestros derechos agrarios...", AHPL.

\section{Bibliografía}

Castro Apreza, Inés, 2006, Transformaciones politicas contemporáneas frente a los usos y costumbres. Mujeres y minorías políticas en Nicolás Ruiz, Chiapas, tesis doctoral, Facultad de Ciencias Políticas y Sociales, Universidad Nacional Autónoma de México.

,- 2002 , "Violencia y justicia en Chipas. Los operativos policiaco-militares de 1998”, en Roberto BriceñoLeón, (compilador), Violencia, sociedad y justicia en América Latina, Consejo Latinoamericano de Ciencias Sociales, Buenos Aires, Argentina.

Gómez Tagle, Silvia y María Eugenia Valdés Vega, 1997, “Chiapas", en Silvia Gómez Tagle (coordinadora), 1994: las elecciones en los estados, Volumen I, La Jornada Ediciones y Centro de Investigaciones Interdisciplinarias en Ciencias y Humanidades/UNAM, México

Guillén, Diana, 1998, Chiapas 1973-1993. Mediaciones, politica e institucionalidad, Instituto Mora, México.

Harvey, Neil, 2000 [1998], La rebelión de Chiapas. La lucha por la tierra y la democracia, Era, México.

Kymlicka, Will, 1996 [1995], Ciudadanía multicultural (Barcelona: Paidós).

Leyva Solano, Xochitl, 1999, "De las Cañadas a Europa: niveles, actores y discursos del Nuevo Movimiento 
Nicolás Ruiz: La LUCHa CONTRA El Estado y La

RESTRICCIÓN INTERNA DE DERECHOS

Zapatista (NMZ) (1994-1997)”, en Desacatos. Revista de antropología social no 1, CIESAS, México.

Leyva, Xochitl y Shannon Speed, 2001, "Los derechos humanos en Chiapas: del "discurso globalizado" a la “gramática moral”, en Pedro Pitarch y Julián López García (editores), Los derechos humanos en tierras mayas. Politica, representaciones y moralidad, Sociedad Español de Estudios Mayas, Madrid.

Lisbona, Miguel, 1992, "Un intercambio ritual entre dos pueblos de Chiapas: Totolapa y Nicolás Ruiz”, en Revista del CONSEJO, núm. 6, Tuxtla Gutiérrez, Consejo Estatal de Fomento a la Investigación y Difusión de la Cultura/Gobierno del Estado de Chiapas, 1992.

Mier y Terán Jiménez Cacho, Mateo, (2004), Autonomía zapatista en Altamirano, Chiapas. Estudio de vidas del Municipio Autónomo "17 de Noviembre", Tesis de licenciatura en Ciencia Política y Relaciones Internacionales, Centro de Investigación y Docencia Económicas, A.C., México.

Molinar Horcasitas, Juan, (1991), El tiempo de la legitimidad. Elecciones, autoritarismo y democracia en México, Cal y Arena, México.

Pasquel, Lourdes de León (coord.), 2001, Costumbres, leyes y movimiento indio en Oaxaca y Chiapas, CIESAS-Miguel Ángel Porrúa, México.

Rus, Jan, 1995 [1994], "La comunidad revolucionaria institucional”, en Juan Pedro Viqueira y Mario Humberto Ruz, Chiapas. Los rumbos de otra historia, Centro de Estudios Mayas del Instituto de Investigaciones Filológicas y Coordinación de Humanidades-
UNAM-Centro de Investigaciones Superiores en Antropología Social, Centro de Estudios Mexicanos y Centroamericanos-Universidad de Guadalajara, México.

Speed, Shannon, 2004, "Lucha por la tierra, globalización e identidad: la etnohistoria y el etnopresente de Nicolás Ruiz", en Maya Lorena Pérez, Tejiendo historias. Tierra, género y poder en Chiapas, Colección Científica, Instituto Nacional de Antropología e Historia, México.

Sonnleitner, Willibald, 2001, Los indígenas y la democratización electoral. Una década de cambio político entre los trotziles y treltales de Los Altos de Chiapas (1988-2000), (México: El Colegio de México-Instituto Federal Electoral).

Van Der Haar, Gemma, 2004, “Autonomía a ras de tierra: algunas implicaciones y dilemas de la autonomía zapatista en la práctica”, en Maya Lorena Pérez, Tejiendo historias. Tierra, género y poder en Chiapas, Colección Científica, Instituto Nacional de Antropología e Historia, México.

Viqueira, Juan Pedro, 2002, "La comunidad indígena en México en los estudios antropológicos e históricos", en Encrucijadas chiapanecas, Tusquets Editores-Colegio de México, México.

Viqueira, Juan Pedro y Willibald Sonnleitner (coordinadores), 2000, Democracia en tierras indígenas. Las elecciones en Los Altos de Chiapas (1991-1998), Centro de Investigaciones y Estudios Superiores en Antropología Social, El Colegio de México, Instituto Federal Electoral, México. 